\title{
Microcontainers for oral insulin delivery - In vitro studies of permeation enhancement
}

\author{
Jørgensen, Jacob Rune; Jepsen, Morten Leth; Nielsen, Line Hagner; Dufva, Martin; Nielsen, Hanne \\ Mørck; Rades, Thomas; Boisen, Anja; Müllertz, Anette
}

\author{
Published in: \\ European Journal of Pharmaceutics and Biopharmaceutics
}

Link to article, DOI:

10.1016/j.ejpb.2019.08.011

Publication date:

2019

Document Version

Peer reviewed version

Link back to DTU Orbit

Citation (APA):

Jørgensen, J. R., Jepsen, M. L., Nielsen, L. H., Dufva, M., Nielsen, H. M., Rades, T., Boisen, A., \& Müllertz, A. (2019). Microcontainers for oral insulin delivery - In vitro studies of permeation enhancement. European Journal of Pharmaceutics and Biopharmaceutics, 143, 98-105. https://doi.org/10.1016/j.ejpb.2019.08.011

\section{General rights}

Copyright and moral rights for the publications made accessible in the public portal are retained by the authors and/or other copyright owners and it is a condition of accessing publications that users recognise and abide by the legal requirements associated with these rights.

- Users may download and print one copy of any publication from the public portal for the purpose of private study or research.

- You may not further distribute the material or use it for any profit-making activity or commercial gain

- You may freely distribute the URL identifying the publication in the public portal 


\section{Microcontainers for oral insulin delivery - in vitro studies of permeation enhancement}

2 Jacob Rune Jørgensen ${ }^{\mathrm{a}, \mathrm{b}, \mathrm{c}}$, Morten Leth Jepsen ${ }^{\mathrm{a}, \mathrm{c}}$, Line Hagner Nielsen ${ }^{\mathrm{a}, \mathrm{c}}$, Martin Dufva ${ }^{\mathrm{a}, \mathrm{c}}$, Hanne Mørck

3 Nielsen ${ }^{\mathrm{b}}$, Thomas Rades ${ }^{\mathrm{b}, \mathrm{c}}$, Anja Boisen $^{\mathrm{a}, \mathrm{c}}$ and Anette Müllertz ${ }^{\mathrm{b}, \mathrm{c}, \mathrm{d}, *}$

$4{ }^{\mathrm{a}}$ Department of Health Technology, Technical University of Denmark, Ørsteds Plads, 2800 Kgs. Lyngby, Denmark

$5{ }^{\mathrm{b}}$ Department of Pharmacy, University of Copenhagen, Universitetsparken 2, 2100 Copenhagen $\emptyset$, Denmark

$6{ }^{\mathrm{c}}$ The Danish National Research Foundation and Villum Foundation's Center for Intelligent Drug delivery and sensing Using

7 microcontainers and Nanomechanics

$8{ }^{\mathrm{d}}$ Bioneer:FARMA, Department of Pharmacy, University of Copenhagen, Universitetsparken 2, 2100 Copenhagen $\emptyset$, Denmark

e-mails: jacob.r.joergensen@sund.ku.dk, mojep@dtu.dk, lihan@dtu.dk, dufva@dtu.dk, hanne.morck@sund.ku.dk,

11 thomas.rades@ sund.ku.dk, aboi@dtu.dk and anette.mullertz@ sund.ku.dk*

12 * corresponding author

14 Abstract

15 Oral delivery of peptides is challenging due to their low uptake through the small intestinal epithelium. Tight 16 junctions, connecting the enterocytes, impede permeability, often necessitating the use of permeation enhancers 17 in the formulation. Loading of peptide and permeation enhancer into micro-scale devices, such as 18 microcontainers, can potentially confine the effective absorptive area through unidirectional release and thereby 19 enhance absorption. This concept is investigated by in vitro permeation studies of insulin across Caco- 2 cell and 20 Caco-2/HT29-MTX-E12 co-culture monolayers mimicking the intestinal absorption barrier. The importance of 21 proximity between the microcontainers and the barrier is assessed, by keeping the amounts of insulin and sodium caprate fixed throughout all experiments, while collectively orienting the unidirectional release towards the cell monolayers. Increasing the distance is observed to have a negative effect on insulin permeation matching a onephase exponential decay function, while no difference in insulin transport is observed between Caco-2 and coculture monolayers. Although there are no signs of cytotoxicity caused by the microcontainer material, reversible cell deterioration, as a consequence of high local concentrations of sodium caprate, becomes evident upon qualitative assessment of the cell monolayers. These results both suggest a potential of increasing oral bioavailability of peptides by the use of microcontainers, while simultaneously visualising the ability of regaining monolayer integrity upon local permeation enhancer induced toxicity.

30 Keywords: oral peptides; micro devices; permeation enhancers; sodium caprate $\left(\mathrm{C}_{10}\right)$; Caco-2 cells. 


\section{Introduction}

2 Oral delivery of macromolecules has been a major aim in drug delivery ever since the discovery of insulin in the 1920s (Moroz et al., 2016). The field has seen significant progress within the last decade, resulting in several oral peptide formulations advancing to phase II and III clinical trials. However, only two oral dosage forms for systemic delivery of peptides with molecular sizes higher than $500 \mathrm{Da}$ have reached the market, namely; Neoral $^{\circledR} /$ Sandimmune ${ }^{\circledR}$ (Cyclosporine A, Novartis) and Minirin ${ }^{\circledR}$ (Desmopressin, Ferring Pharmaceuticals) (Aguirre et al., 2016). Regardless of which peptide or protein is attempted for oral delivery, the main challenges come down to their relatively large size, hydrophilicity and chemical predisposition to degradation; all together leading to low oral bioavailability (Moroz et al., 2016; Smart et al., 2014). Protecting peptides from both $\mathrm{pH}$ and enzyme catalysed degradation in the stomach has largely been achieved by enteric coatings, leaving the intestinal environment as the main focus of developing delivery strategies (Felton and Porter, 2013; Thakral et al., 2013). As dissolution of the enteric coating makes the peptide accessible to intestinal enzymes, further enzymatic protection is often incorporated in oral formulations. Locally decreasing the $\mathrm{pH}$ below the optimal conditions for enzymatic activity by co-release of citric acid or direct inhibition using competitive peptidase inhibitors are two of such approaches (Bernkop-Schnürch, 1998; Welling et al., 2014).

However, increasing the fraction of native peptide reaching the enterocytes through gastric protection and enzyme inhibition will not necessarily lead to higher bioavailability, as the permeability of peptides is hindered by their aforementioned physicochemical properties. Overcoming the challenge of gaining peptide transport across the enterocytes and into the bloodstream has been thoroughly investigated by the use of permeation enhancers (Maher et al., 2016). By their interaction with the protein complexes forming the inter-enterocyte connections, known as tight junctions, the paracellular transport of larger hydrophilic molecules can be facilitated (Lindmark et al., 1998; Taverner et al., 2015). Several other interesting approaches in the field of macromolecular absorption enhancement have likewise shown promising properties, such as liposome formulations, cell-penetrating peptides and microneedle-based delivery devices (Abramson et al. 2019; Nielsen et al., 2014; Parmentier et al., 2010; Traverso et al. 2015). Nevertheless, commercially available peptides for oral delivery are currently limited to a mass of $1.2 \mathrm{kDa}$ (Aguirre et al., 2016). Consequently, there is a need for novel strategies for systemic delivery upon oral administration of larger macromolecules, such as the $5.8 \mathrm{kDa}$ dipeptide hormone, insulin, and glucagon-like peptide-1 (GLP-1) agonists both used in the treatment of diabetes mellitus.

9 Perhaps counter-intuitively, the large surface area $\left(>30 \mathrm{~m}^{2}\right)$ of the small intestine (Helander and Fändriks, 2014) 60 might be a disadvantage when delivering peptides. As peptide and excipients are released, they are diluted in the 61 fluid along the epithelium often leading to fast absorption of the permeation enhancer (Buckley et al., 2018). 
62 Potentially, this might lead to local permeation enhancer concentrations below their effective threshold and

63 further to a reduced degree of peptide-permeation enhancer co-localisation. Spatial proximity has recently been

64 shown to be crucial for the gastric uptake of the GLP-1 analog, semaglutide, which is governed by the 65 permeation enhancer sodium $N$-[8-(2-hydroxybenzoyl) aminocaprylate] SNAC being present at a very confined 66 area under and around the site of tablet disintegration (Buckley et al., 2018). Increasing the amount of drug and 67 excipients is a way of compensating for the dilution effect in the gastrointestinal tract (GI-tract), however, higher 68 doses will result in more expensive formulations, as well as larger dosage forms. Alternatively, the dilution 69 could be reduced by confining the effective absorptive area of the intestine by the use of micro-fabricated 70 delivery systems capable of unidirectional release. Such micro-devices have previously shown the potential to 71 increase oral bioavailability of small molecules in rodents compared to controls of the same dose either in 72 solution or as powder in capsules (Chirra et al., 2014; Mazzoni et al., 2017). Moreover, another study reported a 73 tendency of the cylindrical-shaped microcontainers to become embedded in the intestinal mucus in rats (Nielsen 74 et al., 2016). As this behaviour could minimise the release of the encapsulated microcontainer content into the 75 intestinal lumen and thus lower the risk of enzymatic degradation, such unidirectionally releasing devices are of 76 77 et al., 2004). significant interest for oral delivery of peptides (Ahmed et al., 2002; Banerjee and Mitragotri, 2017; Whitehead

78 In this study, the concept of utilising microcontainers to improve insulin permeation was investigated across 79 Caco-2 cell culture and mucus-secreting Caco-2/HT29-MTX-E12 co-culture monolayers. Unidirectional release 80 was optimised by collectively orientating the openings of the microcontainers towards the cell monolayers, while 81 the amounts of permeation enhancer and insulin were kept constant throughout all the studies. This allowed for 82 the assessment of the direct effect of proximity on insulin transport, by manipulating the distance between the 83 monolayers and the point of release from the microcontainers. Distances similar to the thickness of mucus along the GI-tract of laboratory animals were chosen $(0.2-2 \mathrm{~mm})$ (Atuma et al., 2001; Varum et al., 2012). For all the 85 studies, the medium chain fatty acid, sodium caprate $\left(\mathrm{C}_{10}\right)$, was used, due to its ability to enhance paracellular 86 permeation (Lindmark et al., 1998; Maher et al., 2009). Furthermore, the importance of insulin and $\mathrm{C}_{10}$ co87 localisation was evaluated by loading microcontainers either with a mixture of the two components $(1: 1 \mathrm{w} / \mathrm{w})$ or by loading the single components into separate microcontainers prior to the transport studies. 


\section{2. Materials and methods}

\section{2.1. Materials}

94 Silicon wafers (4" (100) $n$-type) were obtained from Okmetic (Vantaa, Finland). SU-8 2075 and SU-8 Developer

95

96

97

98

99

100

101

102

103

104

105

106

107

108

109

110

111

112

113

114

115

116

117

118

119

120

121 were acquired from Micro Resist Technology (Berlin, Germany). Human recombinant insulin, bovine serum albumin (BSA), 4-(2-hydroxyethyl)piperazine-1-ethanesulfonic acid (HEPES), Triton ${ }^{\mathrm{TM}} \mathrm{X}-100$, Dulbecco's Modified Eagle's Medium (DMEM), penicillin-streptomycin, L-glutamine and MEM non-essential amino acid solution (100x) were all purchased from Sigma-Aldrich (St. Louis, MO, USA). $n$-Capric acid sodium salt $\left(\mathrm{C}_{10}\right)$ was obtained from abcr (Karlsruhe, Germany), fetal bovine serum from PAA Laboratories (Pasching, Austria) and trifluoroacetic acid (TFA) from Carl Roth (Karlsruhe, Germany). Hanks' Balanced Salt Solution (HBSS, calcium, magnesium, no phenol red), sodium bicarbonate solution and Hoechst 33342 solution were acquired from Thermo Fisher Scientific (Waltham, MA, USA). 3-(4,5-Dimethylthiazol-2-yl)-5-(3carboxymethoxyphenyl)-2-(4-sulfophenyl)-2H-tetrazolium (MTS) and phenazine methosulfate (PMS) were obtained from Promega (Madison, WI, USA). Paraformaldehyde (PFA) 16\% (w/v) aqueous solution was provided by Alfa Aesar (Haverhill, MA, USA). All other chemicals and solvents were of at least analytical grade and obtained from commercial suppliers. Ultrapure water purified by an Ultra Clear UV system (Evoqua Water Technologies, Pittsburgh, PA, USA) was used throughout the studies.

\subsection{Fabrication and filling of microcontainers}

The microcontainers were fabricated with the parameters previously described (Nielsen et al., 2012) based on the published method by Tao et al. (2006). Briefly, the epoxy-based negative photoresist, SU-8, was dispensed and spin coated onto silicon wafers followed by a baking step and lastly UV exposure using a chromium mask creating the base of the microcontainers. These steps were then repeated with the use of a different chromium mask in order to generate the walls of the microcontainers after which the non-polymerised SU-8 was removed from the wafer. The silicon wafers were then cut into chips $\left(12.8 \times 12.8 \mathrm{~mm}^{2}\right)$ each holding 625 microcontainers.

The exact dimensions of the individual microcontainers have previously been determined with an average cavity diameter of $188 \mu \mathrm{m}$ and a volume capacity of $7.5 \mathrm{~nL}$ (Mazzoni et al., 2017). Prior to filling, a shadow mask was aligned on top of the microcontainer chip in order to minimise the amount of powder being distributed between the microcontainers, as previously illustrated (Abid et al., 2017). A powder mixture of insulin and $\mathrm{C}_{10}(1: 1 \mathrm{w} / \mathrm{w})$ was distributed on top of the shadow mask and subsequently loaded into the individual microcontainers by centrifuging the microcontainer chip in a flat-bottomed Falcon ${ }^{\mathrm{TM}}$ tube using a Heraeus Megafuge 16R 
122 Centrifuge (Thermo Fisher Scientific, Waltham, MA, USA) at 3,720 × g for 30-40 s at $21{ }^{\circ} \mathrm{C}$. Any excessive 123 powder, between the microcontainers, was afterwards removed by pressurised air while simultaneously covering 124 the microcontainer openings with a flat silicon chip. Additionally, to investigate the importance of co125 localisation, insulin and $\mathrm{C}_{10}$ were individually filled into each half of the microcontainer chip. This was done by 126 first covering one half of the shadow mask with a layer of tape prior to centrifuging with insulin, upon which the 127 shadow mask was removed and cleaned using pressurised air. Subsequently, the shadow mask was now placed 128 with the tape covering the insulin-filled microcontainers, followed by a second centrifugation step with $C_{10}$. 129 Scanning electron microscopy (SEM) was used to visualise both empty and filled microcontainers using a 130 Hitachi TM3030 tabletop microscope (Hitachi High-Technologies Europe, Krefeld, Germany) with 15 kV 131 accelerating voltage.

\subsection{In vitro permeation studies with insulin}

134 Caco-2 cells (American Type Culture Collection, Manassas, VA, USA) were cultured under conditions and with 135 growth medium as previously described (Larsen et al., 2008). Both Caco-2 cells alone and 1:1 co-cultures of 136 Caco-2 cells and mucus-secreting HT29-MTX-E12 cells (Inserm, Paris, France) were cultured on polycarbonate 137 Transwell $^{\circledR}$ filters with a surface area of $4.67 \mathrm{~cm}^{2}$ and $0.4 \mu \mathrm{m}$ pore size (Corning Costar from Sigma-Aldrich, St. 138 Louis, MO, USA). The Caco-2 cells were used from passage 26-48, and the HT29-MTX-E12 cells from passage 139 55-63. Both Caco-2 and co-culture monolayers were allowed to mature for 21-28 days prior to insulin 140 permeation studies. All studies were conducted from the apical to the basolateral side at $37{ }^{\circ} \mathrm{C}$ using $10 \mathrm{mM}$ 141 HEPES-buffered HBSS (hHBSS) containing BSA $(0.05 \% \mathrm{w} / \mathrm{v})$. Solubilisation of both insulin and $\mathrm{C}_{10}$ in the 142 hHBSS was ensured by adjusting the $\mathrm{pH}$ of both the donor and receptor compartment to 7.4, i.e. above the $\mathrm{pKa}$ 143 of $\mathrm{C}_{10}$ of 6.5-7.2 (Kanicky et al., 2000; Maher et al., 2016) and more than two units above the isoelectric point of 144 insulin of 5.3 (Iyire et al., 2016). The cells were washed two times with hHBSS after which $1.50 \mathrm{~mL}$ and 2.60 $145 \mathrm{~mL}$ hHBSS were added to the apical and basolateral side, respectively. The study was initiated by gently placing 146 a chip of microcontainers either directly on top of the monolayer $(d=0.0 \mathrm{~mm})$ or at defined distances $(d=0.2$, 1470.5 , or $2.0 \mathrm{~mm}$ ). Placement of the microcontainers upside down was possible without loaded powder falling out, 148 due to its centrifugal compaction. The fixed distances were achieved by using custom-made 149 polytetrafluoroethylene (PTFE) carvings (Fig. 1).

150 A control group was included in which a chip of empty microcontainers was placed directly on the monolayer 151 together with a solution of $0.1 \mathrm{mM}$ insulin and $3 \mathrm{mM} \mathrm{C}_{10}(1: 1 \mathrm{w} / \mathrm{w})$ in hHBSS. These concentrations were 152 calculated based on a maximal loading capacity of $1.6 \mathrm{mg}$ of insulin: $\mathrm{C}_{10}(1: 1 \mathrm{w} / \mathrm{w})$ powder mixture per 
microcontainer chip and an apical volume of $1.50 \mathrm{~mL}$. The permeation study was then carried out with orbital shaking (Compact Shaker KS 15 A, Edmund Bühler, Bodelshausen, Germany) of $75 \mathrm{rpm}$ for $2 \mathrm{~h}$ at $37{ }^{\circ} \mathrm{C}$ with basolateral sampling of $100 \mu \mathrm{L}$ at $15,30,45,60,90$ and 120 min. Each sample was replaced with $100 \mu \mathrm{L}$ preheated hHBSS to maintain a basolateral volume of $2.60 \mathrm{~mL}$. Samples were stored at $-20{ }^{\circ} \mathrm{C}$ until quantification by reversed phase high-performance liquid chromatography (RP-HPLC). Cumulated transported percentages of the total amount of insulin were calculated by including the apical concentration at $120 \mathrm{~min}$. All experiments were performed in triplicates and repeated over three passages $(n=3)$. The Caco-2 cell monolayers were washed twice with hHBSS after the final sampling and evaluated regarding effects on the monolayers. These evaluations were carried out both immediately after the permeation studies, as well as after subsequent incubation periods of $24 \mathrm{~h}$ in growth medium at $5 \% \mathrm{CO}_{2}$ and $37{ }^{\circ} \mathrm{C}$.

\subsection{Insulin quantification by RP-HPLC}

The permeation study samples were analysed by RP-HPLC-UV with $20 \mu \mathrm{L}$ injection volume, using a Dionex UltiMate 3000 system (Thermo Fisher Scientific, Waltham, MA, USA) equipped with a Kinetex XB-C18 column $(100 \times 4.60 \mathrm{~mm}, 5 \mu \mathrm{m}, 100 \AA$ A Phenomenex, Torrance, CA, USA). Elution was done with two mobile phases: A: TFA in water $(0.1 \% \mathrm{v} / \mathrm{v})$ and $\mathrm{B}$ : TFA in acetonitrile $(0.1 \% \mathrm{v} / \mathrm{v})$ with a gradient of $0-3 \mathrm{~min} \mathrm{~A}-\mathrm{B}(75: 25$ v/v) to A-B (20:80 v/v), 3-3.5 min A-B (20:80 v/v) to A-B (75:25 v/v), and 3.5-4.5 min A-B (75:25 v/v) and a flow rate of $1.0 \mathrm{~mL} / \mathrm{min}$ at $22{ }^{\circ} \mathrm{C}$. Quantification of insulin was determined as the area under the curve (AUC) of the UV-absorbance peak at $214 \mathrm{~nm}$ with retention time of $2.7 \mathrm{~min}$. A new insulin standard curve ranging from 2$100 \mu \mathrm{g} / \mathrm{mL}(\mathrm{LOD}=0.25 \mu \mathrm{g} / \mathrm{ml})$ was prepared for each day of quantitative analysis.

\subsection{Caco-2 monolayer integrity and viability}

Transepithelial electrical resistance (TEER) was measured across the monolayers to assess their integrity using an Epithelial Volt/Ohm Meter (EVOM) (World Precision Instruments, Sarasota, FL, USA) with Endohm chambers. Measurements were performed before and after the transport studies, as well as upon recovery after $24 \mathrm{~h}$ of incubation under the same conditions as during culturing (Larsen et al., 2008). Cell viability after $2 \mathrm{~h}$ of transport was evaluated for the cells having a chip of microcontainers loaded with insulin- $\mathrm{C}_{10}$ powder mixture at $d=0.0 \mathrm{~mm}$. For this, a cell metabolic assay (MTS/PMS) was implemented and compared to a control group of Caco-2 cells only being exposed to exchange of growth medium to hHBSS. A solution of MTS $(240 \mu \mathrm{g} / \mathrm{mL})$ and 
182 PMS $(2.4 \mu \mathrm{g} / \mathrm{mL})$ in hHBSS was prepared immediately before use and $1.5 \mathrm{~mL}$ was added to the apical side of 183 the wells. The plate was then protected from light and incubated at $37^{\circ} \mathrm{C}$ with orbital shaking of $75 \mathrm{rpm}$ for $1 \mathrm{~h}$.

184 Samples of $100 \mu \mathrm{l}$ were taken in triplicates from each well and transferred to a 96-well plate for absorbance 185 measurements at $492 \mathrm{~nm}$ using a Labsystems Multiskan MS 352 Microplate Reader (Labsystems, Finland). Both 186 integrity and viability assays were performed in triplicates and repeated over three passages $(n=3)$.

187

\subsection{Staining and visualisation of Caco-2 cells}

189 Visualisation of cell nuclei was performed either immediately after the transport studies or upon the $24 \mathrm{~h}$

190

191

192

193

194

195

196

197

198

199

200

201

202

203

204

205

206

207

208 recovery period. The Caco-2 cell monolayer only being exposed to hHBSS for $2 \mathrm{~h}$ was visualised for comparison. Fixation of the cells was achieved by incubation of the monolayers in a paraformaldehyde solution in $\mathrm{hHBSS}(4 \% \mathrm{w} / \mathrm{v})$ for $15 \mathrm{~min}$ at room temperature. The cells were then permeabilised with a Triton ${ }^{\mathrm{TM}} \mathrm{X}-100$ aqueous solution $(0.1 \% \mathrm{v} / \mathrm{v})$ for $10 \mathrm{~min}$ after which any excess membrane protein binding sites were blocked with a BSA solution in hHBSS (3\% w/v) for $30 \mathrm{~min}$, both at ambient temperature. Hoechst 33342 staining solution $(1 \mu \mathrm{g} / \mathrm{mL})$, prepared in hHBSS immediately before use, was applied to the cells for 15 min at room temperature while protected from light. The Transwell ${ }^{\circledR}$ filters were then cut out, placed on microscopy slides and visualised at an excitation wavelength of $405 \mathrm{~nm}$ using an LSM 700 scanning confocal microscope (Carl Zeiss, Oberkochen, Germany) with EC Epiplan Neofluar 10×/0.25 HD objective. Images were processed using ImageJ version 1.52a (National Institute of Health, Bethesda, MD, USA).

\subsection{Statistics}

All data were handled using GraphPad Prism version 8.1.2 and expressed as mean \pm standard deviation (SD) unless otherwise stated. Comparisons of insulin transport were based on the slopes derived by linear regression analysis of the transport profiles and defined as significant at p-values below $5 \%(P<0.05)$ and very significant at p-values below $1 \%(P<0.01)$. 


\section{Results and discussion}

210

211

212

213

214

215

216

217

218

219

220

221

222

223

224

225

226

227

228

229

230

231

232

233

234

235

236

237

\subsection{Filling of microcontainers with insulin and $C_{10}$}

Drug and permeation enhancer loading were carried out in one microcontainer chip $\left(12.8 \times 12.8 \mathrm{~mm}^{2}\right)$ at a time each holding 625 microcontainers. Utilising a swinging bucket centrifuge, ensured powder settlement perpendicular to the axis of rotation, thereby compacting the powder into the microcontainers. Combined with a shadow mask, this filling method is especially useful for filling of expensive powders, due to the minimisation of powder accumulation between the microcontainers, which is otherwise difficult to retrieve. Microcontainer chips were successfully filled either with the insulin and $\mathrm{C}_{10}$ powder mixture, or with the individual powders (Fig. 2). HPLC analysis confirmed efficient filling of insulin and $\mathrm{C}_{10}$ at a 1:1 weight ratio upon loading of the powder mixture resulting in $1.2 \pm 0.2 \mathrm{mg}$ of the powder mixture per microcontainer chip, equivalent to an average microcontainer load of $1.0 \mu \mathrm{g}$ of insulin.

\subsection{Distance dependency studies}

Insulin transport was initially monitored across Caco- 2 cell monolayers using varied distances (0-2 mm) between the monolayer and the microcontainers loaded with a mixture of insulin and $C_{10}(1: 1 \mathrm{w} / \mathrm{w})$. The effect of an equivalent amount of insulin and $\mathrm{C}_{10}$ in solution, $0.1 \mathrm{mM}$ and $3 \mathrm{mM}$ respectively, was also tested, together with an empty microcontainer chip. The TEER was measured before and after the $2 \mathrm{~h}$ transport experiments as well as upon a subsequent $24 \mathrm{~h}$ incubation period for the cell monolayers suffering the most significant loss of integrity, due to direct contact with the microcontainers $(d=0.0 \mathrm{~mm})$, (Fig. 3$)$.

Based on the TEER values, the loss of cell integrity induced by $\mathrm{C}_{10}$ increased with decreasing distances between microcontainers and cell monolayer. Although the solution only resulted in a drop in TEER to $71 \%$ of the initial value, the same amount released from microcontainers with $d=0.0 \mathrm{~mm}$ caused a drop to $27 \%$. Regarding the effect of specific concentrations of permeation enhancers, substantial lab-to-lab variability is reported in literature (Maher et al., 2009), yet complete recovery of the TEER value has previously been shown after a decrease to only $10 \%$ of the initial TEER triggered by a $8.5 \mathrm{mM}$ solution of $\mathrm{C}_{10}$ (Brayden et al., 2015). For the current distance-dependency study, the highest risks of irreversible loss of integrity and cell damage were expected in the experiments with $d=0.0 \mathrm{~mm}$, as this likely would result in the highest local concentrations of $\mathrm{C}_{10}$. Incubating these Caco-2 monolayers for $24 \mathrm{~h}$ in growth medium subsequent to exposure, however, proved their capability of regaining $86 \%$ of their initial TEER value. Insulin transport monitored across the Caco-2 
monolayers followed the anticipated trend, i.e. insulin transport rates increased with decreasing distances between monolayer and microcontainers. Despite the fact that insulin permeation is influenced by the interplay of several mechanisms, (e.g. dissolution-/diffusion rates of insulin and $\mathrm{C}_{10}$, and the rate of cell monolayer integrity loss), a relatively simple analysis could be used to fit the data. Plotting the transport rate constants, obtained by linear regression of the transport profiles over $2 \mathrm{~h}$, as a function of the distance $(d)$ identifies the mathematical correlation as a one-phase exponential decay regression (Fig. 4).

Upon release with $d=0.0 \mathrm{~mm}, 18 \%$ of insulin was transported to the basolateral side after $2 \mathrm{~h}$. Even at $\mathrm{d}=2.0$ $\mathrm{mm}$, a significant increase in insulin transport of more than 2-fold was observed compared to the solution (Fig. 6). From the rate constant-distance correlation, it is obvious that mucus, acting as a spacing layer, is likely to have a negative impact on the bioavailability. Based on the exponential equation: $\mathrm{Y}=8.29 \mathrm{e}^{-5.28 \mathrm{x}}+0.57$, a distance increase of $0.13 \mathrm{~mm}$ results in a $50 \%$ decrease of the insulin transport rate through the Caco-2 monolayer, calculated as $\ln (2) / 5.28$. While the thickness of the adherent mucus layer is relatively uniform (25-55 $\mu \mathrm{m}$ ) throughout both rat and pig small intestines (Varum et al., 2012), larger variations of the non-adherent layer have been observed in rats. Thicknesses from 120-200 $\mu \mathrm{m}$ in the duodenum and jejunum to about $500 \mu \mathrm{m}$ in the ileum and almost $1000 \mu \mathrm{m}$ in the colon have been reported (Atuma et al., 2001). Although mucus potentially will have a negative effect on insulin absorption, it serves as a protecting layer throughout the GI-tract partly by minimising the risk of pathogen absorption (Cornick et al., 2015). However, as parallel uptake of e.g. pathogens is a common concern regarding the use of permeation enhancers, further evaluation of the monolayer integrity was performed using confocal laser-scanning microscopy.

\subsection{Qualitative assessment of Caco-2 monolayers}

An MTS/PMS viability assay demonstrated a relative monolayer metabolic activity of $93 \pm 2 \%$ immediately after transport studies with $d=0.0 \mathrm{~mm}$, compared to monolayers, which had only been subjected to exposure of hHBSS. This indicated either a negligible cytotoxic effect of $\mathrm{C}_{10}$ distributed along the monolayer or alternatively more profound effects at local areas. Confocal laser-scanning microscopy images were obtained after staining the Caco-2 cell nuclei with Hoechst 33342 in order to qualitatively assess the local effect caused by $\mathrm{C}_{10}$ during the transport studies (Fig. 5).

Fig. 5A-C show the Caco-2 cell nuclei density immediately after transport studies with $d=0.0,0.2$, and $0.5 \mathrm{~mm}$, respectively. Areas, corresponding to microcontainer openings, of complete absence of Caco-2 cells, were apparent after the $2 \mathrm{~h}$ permeation study with $d=0.0 \mathrm{~mm}$ (Fig. 5A). Despite this pronounced toxic effect on the 
268 Caco-2 cells, the relatively low drop in viability compared to the drop in TEER can be explained by the confined 269 environments of high $\mathrm{C}_{10}$ concentrations. Considering a mean diameter of the microcontainer cavities of $188 \mu \mathrm{m}$, 270 the total area of 625 microcontainers only corresponds to $3.6 \%$ of the total area of the monolayer. Likewise, 271 areas of low Caco-2 cell nuclei densities were visible after a release at $d=0.2 \mathrm{~mm}$ (Fig. 5B). The toxic effects of $272 \mathrm{C}_{10}$, and surfactants in general, are well known at concentrations even below their critical micelle concentration 273 (Maher et al., 2009). In this case the cytotoxicity manifests itself as local disruptions of the monolayer, resulting 274 in the relatively high transport rates for the short microcontainer-monolayer distances $(\mathrm{d}=0.0-0.2 \mathrm{~mm})$, as seen 275 in Fig. 4. However, despite a TEER value decrease to $60 \%$ of the initial value after $2 \mathrm{~h}$ permeation study with $d$ $276=0.5 \mathrm{~mm}$, no variation in the monolayer integrity was observed when visualising the cell nuclei (Fig. 5C), 277 compared to monolayers being subjected to $2 \mathrm{~h}$ exposure of hHBSS (Fig. 5F). This indicates that the 4.2-fold 278 increase in insulin flux, observed with $\mathrm{d}=0.5 \mathrm{~mm}$, compared to the $0.1 \mathrm{mM}$ insulin and $3 \mathrm{mM} \mathrm{C}_{10}$ solution, was 279 triggered by paracellular transport across an intact monolayer, rather than by local deterioration of the barrier.

280 No distinguishable impressions of microcontainers were visible on the cell monolayers after exposure to the 281 solution in combination with a chip of empty microcontainers placed directly on the monolayer (Fig. 5E). 282 Permeation enhancing and cytotoxic effects must therefore be a consequence of high local concentrations of $\mathrm{C}_{10}$, 283 rather than an effect caused by microcontainer material itself. Cell proliferation and/or migration of cells to the 284 compromised areas of the cell monolayers with $d=0.0 \mathrm{~mm}$ was clearly visible upon $24 \mathrm{~h}$ incubation in growth 285 medium, as the areas of complete absence of nuclei had restored some extent of integrity (Fig. 5D) in accordance 286 with the recovering TEER values. A feature unlikely to happen had the whole cell monolayer been exposed to a 287 cytotoxic $\mathrm{C}_{10}$ concentration similar that of the local areas under the microcontainers (Chao et al., 1999; Sakai et 288 al., 1998; Shima et al., 1999).

289 There is an on-going debate regarding the risks of utilising permeation enhancers for oral formulations 290 (McCartney et al., 2016). Certainly, these considerations also need to be taken into account when promoting 291 permeation enhancement through confined high concentrations. The risk of co-absorption is of concern as 292 opening of tight junctions and/or cell membrane perturbation could facilitate the concurrent systemic uptake of 293 e.g., pathogens (McCartney et al., 2016). Although the results obtained from the cell integrity and viability 294 assays did not immediately give rise to any concerns, the confocal images of the monolayers upon $2 \mathrm{~h}$ exposure 295 to high local concentrations of $\mathrm{C}_{10}$ clearly depict the reasons for this debate. Studies on Caco-2 cell monolayers, 296 however, often overestimate toxic effects, due to their lack of in vivo complexity, such as mucus, heterogenic 297 cell type composition, co-factors, and peristalsis altogether resulting in reduced repair functions (McCartney et 298 al., 2016; Swenson et al., 1994). The magnitude of the observed toxic effects are therefore likely to be reduced in 299 the GI-tract, however, further measures might be necessary in case local tissue damage is still observed in vivo. 
300

301

302

303

304

305

306

307

308

309

310

311

312

313

314

315

316

317

318

319

320

321

322

323

324

325

326

327

328

329

Reducing the amount of $\mathrm{C}_{10}$ in the microcontainers or loading of alternative permeation enhancers could resolve potential cytotoxic effects. Permeation enhancers of interest might simply show a broader range between efficient- and cytotoxic concentrations or alternatively work by peptide specific complexation resulting in increased hydrophobicity and thus transcelluar uptake. The latter mechanism has previously claimed to be the cause of enhancement by SNAC (Ding et al., 2004; Malkov et al., 2005). As the absence of mucus on Caco-2 cell monolayers is one of the main differences compared to in vivo conditions, transport studies were also conducted with mucus-secreting co-cultures.

\subsection{Impact of co-localisation with permeation enhancer and mucus on insulin transport}

Insulin transport studies across Caco-2/HT29-MTX-E12 co-culture monolayers were carried out to address the potential negative impact of mucus on insulin permeation, when placing the microcontainer chips directly on the monolayer $(d=0.0 \mathrm{~mm})$. In parallel, the importance of co-localisation was evaluated by the use of microcontainer chips where half of the microcontainers were filled with insulin and the other half with $\mathrm{C}_{10}$. The latter evaluation was likewise carried out on both Caco-2 and co-culture monolayers with $d=0.0 \mathrm{~mm}$ (Fig. 6).

Loading insulin and $\mathrm{C}_{10}$ on each half of the microcontainer chip triggered a 4-5 fold decrease of the insulin transport over $2 \mathrm{~h}$, compared to microcontainers with the powder mixture $(1: 1 \mathrm{w} / \mathrm{w})$, on both monolayer types with $d=0.0 \mathrm{~mm}$. A similar importance of co-localisation has previously been observed when simply controlling the degree of co-localisation of $4 \mathrm{kDa}$ fluorescein isothiocyanate-dextran and $\mathrm{C}_{10}$ by intestinal instillation in rats either together or at staggered time points (Wang et al., 2010). The microcontainer chips with insulin and $\mathrm{C}_{10}$ individually filled, however, still resulted in a 10-fold increase in insulin transport across the Caco-2 monolayer compared to the equivalent mass of insulin and $\mathrm{C}_{10}$ in solution $(0.1 \mathrm{mM}$ and $3 \mathrm{mM}$, respectively), most likely caused by diffusion of insulin to the areas of high local $\mathrm{C}_{10}$ concentrations.

No differences in insulin transport were observed between the mucus-secreting co-culture monolayers and Caco2 cell monolayers. This could simply be due to the weight of the microcontainer chip causing penetration thereby bypassing the mucus layer. However, neither was any difference in insulin transport observed between Caco- 2 cell monolayers and co-culture monolayers from the separately loaded microcontainers, even though the insulin molecules inevitably would need to diffuse along the monolayers in order to undergo transport. This implies that the hydrodynamic size of insulin $(1.5-3.0 \mathrm{~nm}$ ) (Jensen et al., 2014) is sufficiently below the mesh spacing of the mucus, secreted by the HT29-MTX-E12 cells, in order not to be retained. Other studies have previously determined limited diffusivity for peptides of molecular mass above $12.4 \mathrm{kDa}$ in porcine intestinal mucus 
330 (Bernkop-Schnürch and Fragner, 1996) where the pores in such mucus have been determined to range from 100 $331 \mathrm{~nm}$ to several micrometers by cryo-SEM (Boegh and Nielsen, 2015). The mucus layer in vivo is, however, still 332 likely to negatively influence absorption as removal of mucus on rat ileal segments has previously been found to 333 significantly increase insulin transport (Aoki et al., 2005). Although the authors claimed the mucus to 334 predominantly function as an enzymatic barrier, the thickness of the mucus might additionally lead to increased 335 distances between microcontainers and enterocytes.

336 Furthermore, it might be unlikely to imagine an in vivo scenario in which capsule disintegration will result in 337 unanimous optimal orientation of microcontainers, however, our in vitro results strongly indicate the importance 338 of continuous initiatives to improve these parameters. In situ intestinal perfusion studies have previously shown 339 the propensity of microcontainers to become partly embedded in the mucus, thereby shortening the distance to 340 the absorptive barrier lower than that of the mucus thickness (Nielsen et al., 2016). While this might compensate 341 for some degree of suboptimal orientation, further initiatives in order to increase the tendency of unidirectional 342 release towards the barrier remain an important focus of microcontainers as well as for other oral peptide 343 delivery devices (Abramson et al., 2019; Mazzoni et al., 2019; Vaut et al., 2019). 
346 The concept of improving intestinal permeation of insulin by the use of unidirectionally releasing 347 microcontainers in combination with sodium caprate $\left(\mathrm{C}_{10}\right)$ was investigated in in vitro transport studies across 348 Caco-2 cell monolayers and mucus-secreting co-culture monolayers. Decreasing the distance between the point 349 of unidirectional release and the barrier resulted in enhanced insulin permeation, but also increased local 350 cytotoxic effects observed by confocal microscopy. Close proximities $(0.0-0.2 \mathrm{~mm})$ triggered local reversible 351 deteriorations of the barrier, while distances of $0.5-2.0 \mathrm{~mm}$ seemed to prompt non-destructive paracellular 352 permeation enhancement. To which extent local epithelial deterioration is acceptable needs further evaluation in 353 more complex barrier models, in order to assess the true potential of using unidirectionally releasing micro 354 devices in combination with permeation enhancers for oral delivery of insulin.

356 Acknowledgements

357 Lene Grønne Pedersen and Mette Frandsen are acknowledged for their efforts regarding cell culturing. Stephan 358 Sylvest Keller and Lasse Højlund Thamdrup are both thanked for manufacturing of microcontainers. Lasse 359 Johansson is acknowledged for production of the PTFE carvings and Daniel Bar-Shalom is recognised for 360 initiating ideas leading to the method for filling the microcontainers. This work was supported by the Danish 361 National Research Foundation (DNRF122) and Villum Foundation (Grant No. 9301), Center for Intelligent Drug 362 delivery and sensing Using microcontainers and Nanomechanics (IDUN).

\section{Declaration of interest}

365 The authors have no competing interests. 


\section{References}

Abid, Z., Gundlach, C., Durucan, O., von Halling Laier, C., Nielsen, L.H., Boisen, A., Keller, S.S., 2017. Powder embossing method for selective loading of polymeric microcontainers with drug formulation. Microelectron. Eng. 171, 20-24. https://doi.org/10.1016/j.mee.2017.01.018

Abramson, A., Caffarel-Salvador, E., Khang, M., Dellal, D., Silverstein, D., Gao, Y., Frederiksen, M.R., Vegge, A., Hubálek, F., Water, J.J., Friderichsen, A.V., Fels, J., Kirk, R.K., Cleveland, C., Collins, J., Tamang, S., Hayward, A., Landh, T., Buckley, S.T., Roxhed, N., Rahbek, U., Langer, R., Traverso, G., 2019. An ingestible self-orienting system for oral delivery of macromolecules. Science 363, 611-615. https://doi.org/10.1126/science.aau2277

Aguirre, T.A.S., Teijeiro-Osorio, D., Rosa, M., Coulter, I.S., Alonso, M.J., Brayden, D.J., 2016. Current status of selected oral peptide technologies in advanced preclinical development and in clinical trials. Adv. Drug Deliv. Rev., Oral delivery of peptides: Opportunities and issues for translation 106, Part B, 223-241. https://doi.org/10.1016/j.addr.2016.02.004

Ahmed, A., Bonner, C., Desai, T.A., 2002. Bioadhesive microdevices with multiple reservoirs: a new platform for oral drug delivery. J. Control. Release 81, 291-306. https://doi.org/10.1016/S0168-3659(02)00074-3

Aoki, Y., Morishita, M., Takayama, K., 2005. Role of the mucous/glycocalyx layers in insulin permeation across the rat ileal membrane. Int. J. Pharm. 297, 98-109. https://doi.org/10.1016/j.ijpharm.2005.03.004

Atuma, C., Strugala, V., Allen, A., Holm, L., 2001. The adherent gastrointestinal mucus gel layer: thickness and physical state in vivo. Am. J. Physiol.-Gastrointest. Liver Physiol. 280, G922-G929. https://doi.org/10.1152/ajpgi.2001.280.5.G922

Banerjee, A., Mitragotri, S., 2017. Intestinal patch systems for oral drug delivery. Curr. Opin. Pharmacol. 36, 5865. https://doi.org/10.1016/j.coph.2017.08.005

Bernkop-Schnürch, A., 1998. The use of inhibitory agents to overcome the enzymatic barrier to perorally administered therapeutic peptides and proteins. J. Control. Release 52, 1-16. https://doi.org/10.1016/S0168-3659(97)00204-6

Bernkop-Schnürch, A., Fragner, R., 1996. Investigations into the Diffusion Behaviour of Polypeptides in Native Intestinal Mucus with Regard to their Peroral Administration. Pharm. Pharmacol. Commun. 2, 361-363. https://doi.org/10.1111/j.2042-7158.1996.tb00632.x

Boegh, M., Nielsen, H.M., 2015. Mucus as a Barrier to Drug Delivery - Understanding and Mimicking the Barrier Properties. Basic Clin. Pharmacol. Toxicol. 116, 179-186. https://doi.org/10.1111/bcpt.12342

Brayden, D.J., Maher, S., Bahar, B., Walsh, E., 2015. Sodium caprate-induced increases in intestinal permeability and epithelial damage are prevented by misoprostol. Eur. J. Pharm. Biopharm. Off. J. Arbeitsgemeinschaft Pharm. Verfahrenstechnik EV 94, 194-206. https://doi.org/10.1016/j.ejpb.2015.05.013

Buckley, S.T., Bækdal, T.A., Vegge, A., Maarbjerg, S.J., Pyke, C., Ahnfelt-Rønne, J., Madsen, K.G., Schéele, S.G., Alanentalo, T., Kirk, R.K., Pedersen, B.L., Skyggebjerg, R.B., Benie, A.J., Strauss, H.M., Wahlund, P.-O., Bjerregaard, S., Farkas, E., Fekete, C., Søndergaard, F.L., Borregaard, J., HartoftNielsen, M.-L., Knudsen, L.B., 2018. Transcellular stomach absorption of a derivatized glucagon-like peptide-1 receptor agonist. Sci. Transl. Med. 10, eaar7047. https://doi.org/10.1126/scitranslmed.aar7047

Chao, A.C., Nguyen, J.V., Broughall, M., Griffin, A., Fix, J.A., Daddona, P.E., 1999. In vitro and in vivo evaluation of effects of sodium caprate on enteral peptide absorption and on mucosal morphology. Int. J. Pharm. 191, 15-24. https://doi.org/10.1016/S0378-5173(99)00213-6

Chirra, H.D., Shao, L., Ciaccio, N., Fox, C.B., Wade, J.M., Ma, A., Desai, T.A., 2014. Planar Microdevices for Enhanced In Vivo Retention and Oral Bioavailability of Poorly Permeable Drugs. Adv. Healthc. Mater. 3, 1648-1654. https://doi.org/10.1002/adhm.201300676

Cornick, S., Tawiah, A., Chadee, K., 2015. Roles and regulation of the mucus barrier in the gut. Tissue Barriers 3. https://doi.org/10.4161/21688370.2014.982426 
Ding, X., Rath, P., Angelo, R., Stringfellow, T., Flanders, E., Dinh, S., Gomez-Orellana, I., Robinson, J.R., 2004. Oral Absorption Enhancement of Cromolyn Sodium Through Noncovalent Complexation. Pharm. Res. 21, 2196-2206. https://doi.org/10.1007/s11095-004-7671-9

Felton, L.A., Porter, S.C., 2013. An update on pharmaceutical film coating for drug delivery. Expert Opin. Drug Deliv. 10, 421-435. https://doi.org/10.1517/17425247.2013.763792

Helander, H.F., Fändriks, L., 2014. Surface area of the digestive tract - revisited. Scand. J. Gastroenterol. 49, 681-689. https://doi.org/10.3109/00365521.2014.898326

Iyire, A., Alayedi, M., Mohammed, A.R., 2016. Pre-formulation and systematic evaluation of amino acid assisted permeability of insulin across in vitro buccal cell layers. Sci. Rep. 6. https://doi.org/10.1038/srep32498

Jensen, S.S., Jensen, H., Cornett, C., Møller, E.H., Østergaard, J., 2014. Insulin diffusion and self-association characterized by real-time UV imaging and Taylor dispersion analysis. J. Pharm. Biomed. Anal. 92, 203-210. https://doi.org/10.1016/j.jpba.2014.01.022

Kanicky, J.R., Poniatowski, A.F., Mehta, N.R., Shah, D.O., 2000. Cooperativity among Molecules at Interfaces in Relation to Various Technological Processes: Effect of Chain Length on the pKa of Fatty Acid Salt Solutions. Langmuir 16, 172-177. https://doi.org/10.1021/la990719o

Larsen, M., Larsen, B.B., Frølund, B., Nielsen, C.U., 2008. Transport of amino acids and GABA analogues via the human proton-coupled amino acid transporter, hPAT1: Characterization of conditions for affinity and transport experiments in Caco-2 cells. Eur. J. Pharm. Sci. 35, 86-95. https://doi.org/10.1016/j.ejps.2008.06.007

Lindmark, T., Schipper, N., Lazorová, L., Boer, A.G.D., Artursson, P., 1998. Absorption Enhancement in Intestinal Epithelial Caco-2 Monolayers by Sodium Caprate: Assessment of Molecular Weight Dependence and Demonstration of Transport Routes. J. Drug Target. 5, 215-223. https://doi.org/10.3109/10611869808995876

Maher, S., Leonard, T.W., Jacobsen, J., Brayden, D.J., 2009. Safety and efficacy of sodium caprate in promoting oral drug absorption: from in vitro to the clinic. Adv. Drug Deliv. Rev., 2009 Editors' Collection 61, 1427-1449. https://doi.org/10.1016/j.addr.2009.09.006

Maher, S., Mrsny, R.J., Brayden, D.J., 2016. Intestinal permeation enhancers for oral peptide delivery. Adv. Drug Deliv. Rev., Oral delivery of peptides: Opportunities and issues for translation 106, Part B, 277319. https://doi.org/10.1016/j.addr.2016.06.005

Malkov, D., Angelo, R., Wang, H., Flanders, E., Tang, H., Gomez-Orellana, I., 2005. Oral delivery of insulin with the eligen technology: mechanistic studies. Curr. Drug Deliv. 2, 191-197.

Mazzoni, C., Jacobsen, R.D., Mortensen, J., Jørgensen, J.R., Vaut, L., Jacobsen, J., Gundlach, C., Müllertz, A., Nielsen, L.H., Boisen, A., 2019. Polymeric Lids for Microcontainers for Oral Protein Delivery. Macromol. Biosci. 19, 1900004. https://doi.org/10.1002/mabi.201900004

Mazzoni, C., Tentor, F., Strindberg, S.A., Nielsen, L.H., Keller, S.S., Alstrøm, T.S., Gundlach, C., Müllertz, A., Marizza, P., Boisen, A., 2017. From concept to in vivo testing: Microcontainers for oral drug delivery. J. Control. Release 268, 343-351. https://doi.org/10.1016/j.jconrel.2017.10.013

McCartney, F., Gleeson, J.P., Brayden, D.J., 2016. Safety concerns over the use of intestinal permeation enhancers: A mini-review. Tissue Barriers 4. https://doi.org/10.1080/21688370.2016.1176822

Moroz, E., Matoori, S., Leroux, J.-C., 2016. Oral delivery of macromolecular drugs: Where we are after almost 100years of attempts. Adv. Drug Deliv. Rev. 101, 108-121. https://doi.org/10.1016/j.addr.2016.01.010

Nielsen, E.J.B., Yoshida, S., Kamei, N., Iwamae, R., Khafagy, E.-S., Olsen, J., Rahbek, U.L., Pedersen, B.L., Takayama, K., Takeda-Morishita, M., 2014. In vivo proof of concept of oral insulin delivery based on a co-administration strategy with the cell-penetrating peptide penetratin. J. Control. Release 189, 19-24. https://doi.org/10.1016/j.jconrel.2014.06.022

Nielsen, L.H., Keller, S.S., Gordon, K.C., Boisen, A., Rades, T., Müllertz, A., 2012. Spatial confinement can lead to increased stability of amorphous indomethacin. Eur. J. Pharm. Biopharm. 81, 418-425. https://doi.org/10.1016/j.ejpb.2012.03.017 
Nielsen, L.H., Melero, A., Keller, S.S., Jacobsen, J., Garrigues, T., Rades, T., Müllertz, A., Boisen, A., 2016. Polymeric microcontainers improve oral bioavailability of furosemide. Int. J. Pharm. 504, 98-109. https://doi.org/10.1016/j.ijpharm.2016.03.050

Parmentier, J., Hartmann, F.J., Fricker, G., 2010. In vitro evaluation of liposomes containing bio-enhancers for the oral delivery of macromolecules. Eur. J. Pharm. Biopharm. 76, 394-403. https://doi.org/10.1016/j.ejpb.2010.09.002

Sakai, M., Imai, T., Ohtake, H., Otagiri, M., 1998. Biopharmaceutics: Cytotoxicity of Absorption Enhancers in Caco-2 Cell Monolayers. J. Pharm. Pharmacol. 50, 1101-1108. https://doi.org/10.1111/j.20427158.1998.tb03319.x

Shima, M., Kimura, Y., Adachi, S., Matsuno, R., 1999. Recovery of Caco-2 Cell Monolayers to Normal from the Transport-enhanced State Induced by Capric Acid Sodium Salt and its Monoacylglycerol. Biosci. Biotechnol. Biochem. 63, 680-687. https://doi.org/10.1271/bbb.63.680

Smart, A.L., Gaisford, S., Basit, A.W., 2014. Oral peptide and protein delivery: intestinal obstacles and commercial prospects. Expert Opin. Drug Deliv. 11, 1323-1335. https://doi.org/10.1517/17425247.2014.917077

Swenson, E.S., Milisen, W.B., Curatolo, W., 1994. Intestinal Permeability Enhancement: Efficacy, Acute Local Toxicity, and Reversibility. Pharm. Res. 11, 1132-1142. https://doi.org/10.1023/A:1018984731584

Tao, S.L., Popat, K., Desai, T.A., 2006. Off-wafer fabrication and surface modification of asymmetric 3D SU-8 microparticles. Nat. Protoc. 1, 3153-3158. https://doi.org/10.1038/nprot.2006.451

Taverner, A., Dondi, R., Almansour, K., Laurent, F., Owens, S.-E., Eggleston, I.M., Fotaki, N., Mrsny, R.J., 2015. Enhanced paracellular transport of insulin can be achieved via transient induction of myosin light chain phosphorylation. J. Control. Release 210, 189-197. https://doi.org/ 10.1016/j.jconrel.2015.05.270

Thakral, S., Thakral, N.K., Majumdar, D.K., 2013. Eudragit®: a technology evaluation. Expert Opin. Drug Deliv. 10, 131-149. https://doi.org/10.1517/17425247.2013.736962

Traverso, G., Schoellhammer, C.M., Shroeder, A., Maa, R., Lauwers, G.Y., Polat, B.E., Anderson, D.G., Blankschtein, D., Langer, R., 2015. Microneedles for Drug Delivery via the Gastrointestinal Tract. J. Pharm. Sci. 104, 362-367. https://doi.org/ 10.1002/jps.24182

Varum, F.J.O., Veiga, F., Sousa, J.S., Basit, A.W., 2012. Mucus thickness in the gastrointestinal tract of laboratory animals. J. Pharm. Pharmacol. 64, 218-227. https://doi.org/10.1111/j.20427158.2011.01399.x

Vaut, L., 2019. Additive Manufacturing and Characterization of Mini Devices for Oral Drug Delivery. PhD Thesis, Technical University of Denmark.

Wang, X., Maher, S., Brayden, D.J., 2010. Restoration of rat colonic epithelium after in situ intestinal instillation of the absorption promoter, sodium caprate. Ther. Deliv. 1, 75-82. https://doi.org/10.4155/tde.10.5

Welling, S.H., Hubálek, F., Jacobsen, J., Brayden, D.J., Rahbek, U.L., Buckley, S.T., 2014. The role of citric acid in oral peptide and protein formulations: Relationship between calcium chelation and proteolysis inhibition. Eur. J. Pharm. Biopharm. 86, 544-551. https://doi.org/10.1016/j.ejpb.2013.12.017

Whitehead, K., Shen, Z., Mitragotri, S., 2004. Oral delivery of macromolecules using intestinal patches: applications for insulin delivery. J. Control. Release 98, 37-45. https://doi.org/10.1016/j.jconrel.2004.04.013 


\section{Figures}

504

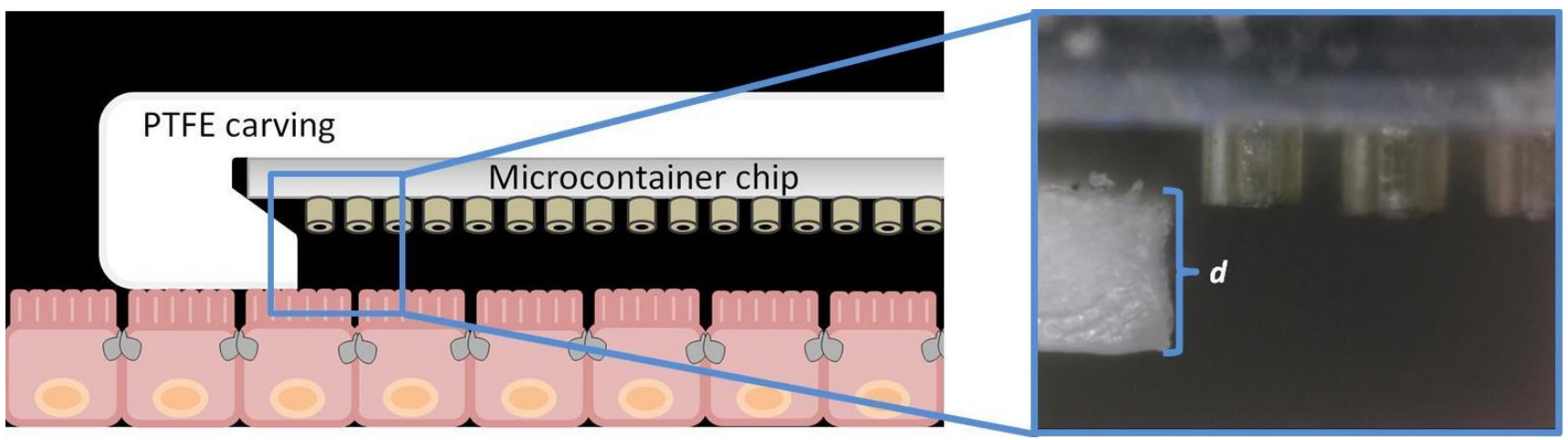

505 Fig. 1. Left: Illustration of the permeation study setup using polytetrafluoroethylene (PTFE) carvings to control

506 the distance between the microcontainer chip and the Caco-2 cell monolayer. Right: Micrograph of a 507 microcontainer chip elevated $0.5 \mathrm{~mm}$ by a PTFE carving, with depiction of dimension, $d$, ensuring exact 508 microcontainer-monolayer distance. Visualised using a Dino-Lite Premier AM7013MZT digital microscope 509 (AnMo Electronics Corporation, Taiwan).

510

511

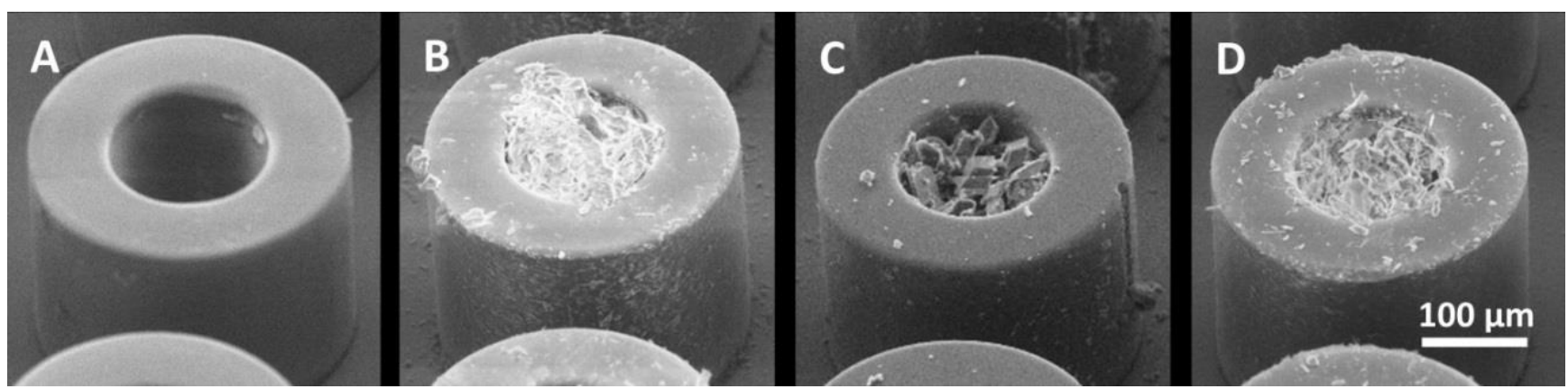

512 Fig. 2. Representative SEM images of microcontainers. A: empty, B: loaded with insulin and $\mathrm{C}_{10}(1: 1 \mathrm{w} / \mathrm{w}), \mathrm{C}$ :

513 loaded with insulin, D: loaded with $\mathrm{C}_{10}$ 


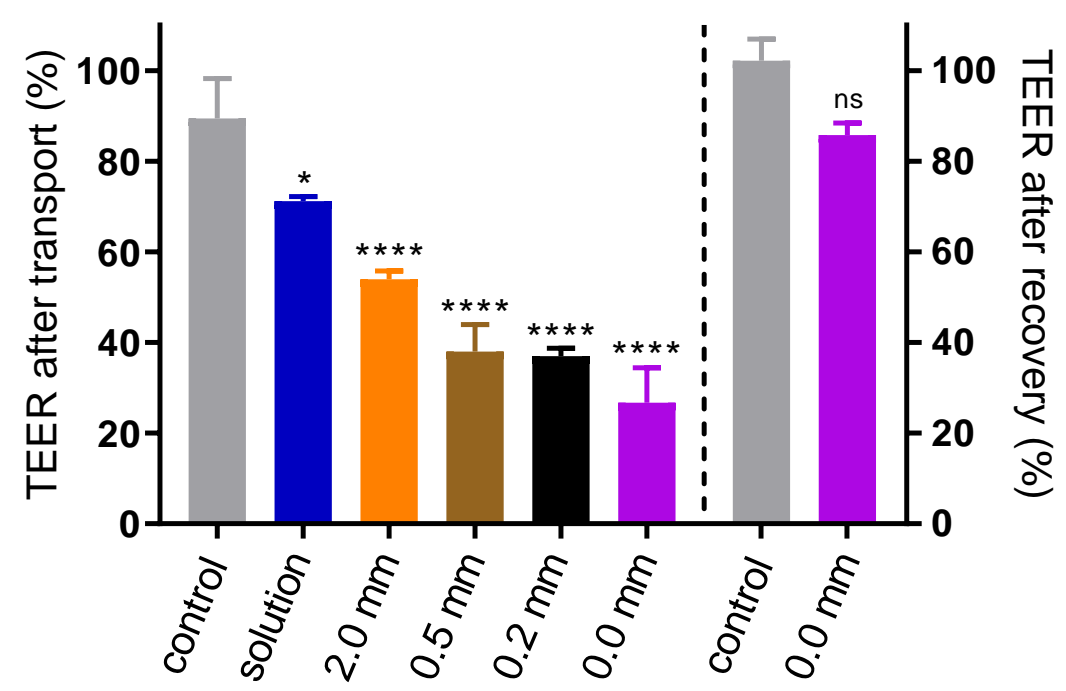

515

516 Fig. 3. TEER values of the Caco-2 cell monolayers after the $2 \mathrm{~h}$ permeation study (left of the dotted line) and 517 after subsequent $24 \mathrm{~h}$ recovery (right of the dotted line) with different distances $(0-2.0 \mathrm{~mm})$ between the 518 microcontainer chips and the cells. The solution consisted of $0.1 \mathrm{mM}$ insulin and $3 \mathrm{mM} \mathrm{C} \mathrm{C}_{10}(1: 1 \mathrm{w} / \mathrm{w})$ in 519 combination with an empty microcontainer chip with direct contact to the monolayer. Control cells were 520 exposed to $2 \mathrm{~h}$ in fresh $10 \mathrm{mM}$ hHBSS. Expressed as percentages of initial TEER values; mean + SD $(\mathrm{n} \geq 3)$. 521 Absolute values of the initial TEER was $278 \pm 17 \Omega \mathrm{cm}^{2}$ (mean $\pm \mathrm{SD}, \mathrm{n}=7$ ). $* P<0.1, * * * * P<0.0001$ compared 522 to control TEER after transport and $n s$ : not significant, $P>0.05$, compared to control TEER after recovery based on a 523 Tukey's multiple comparisons one-way ANOVA test.

524

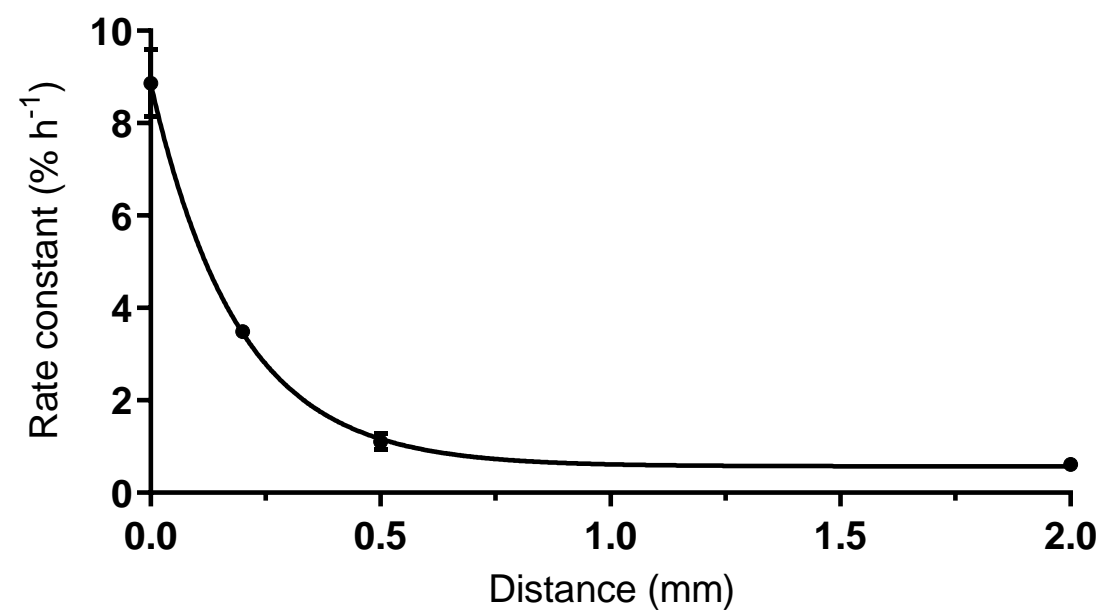


526 Fig. 4. Exponential decay regression of the insulin transport rate as a function of the distance between the 527 microcontainer chip and Caco-2 cell monolayer. Expressed as mean \pm SD $(n \geq 3)$. A one phase decay (least 528 squares) fitting analysis was done using GraphPad Prism resulting in the equation: $Y=8.29 e^{-5.28 x}+$ $5290.57, R^{2}=0.904$.
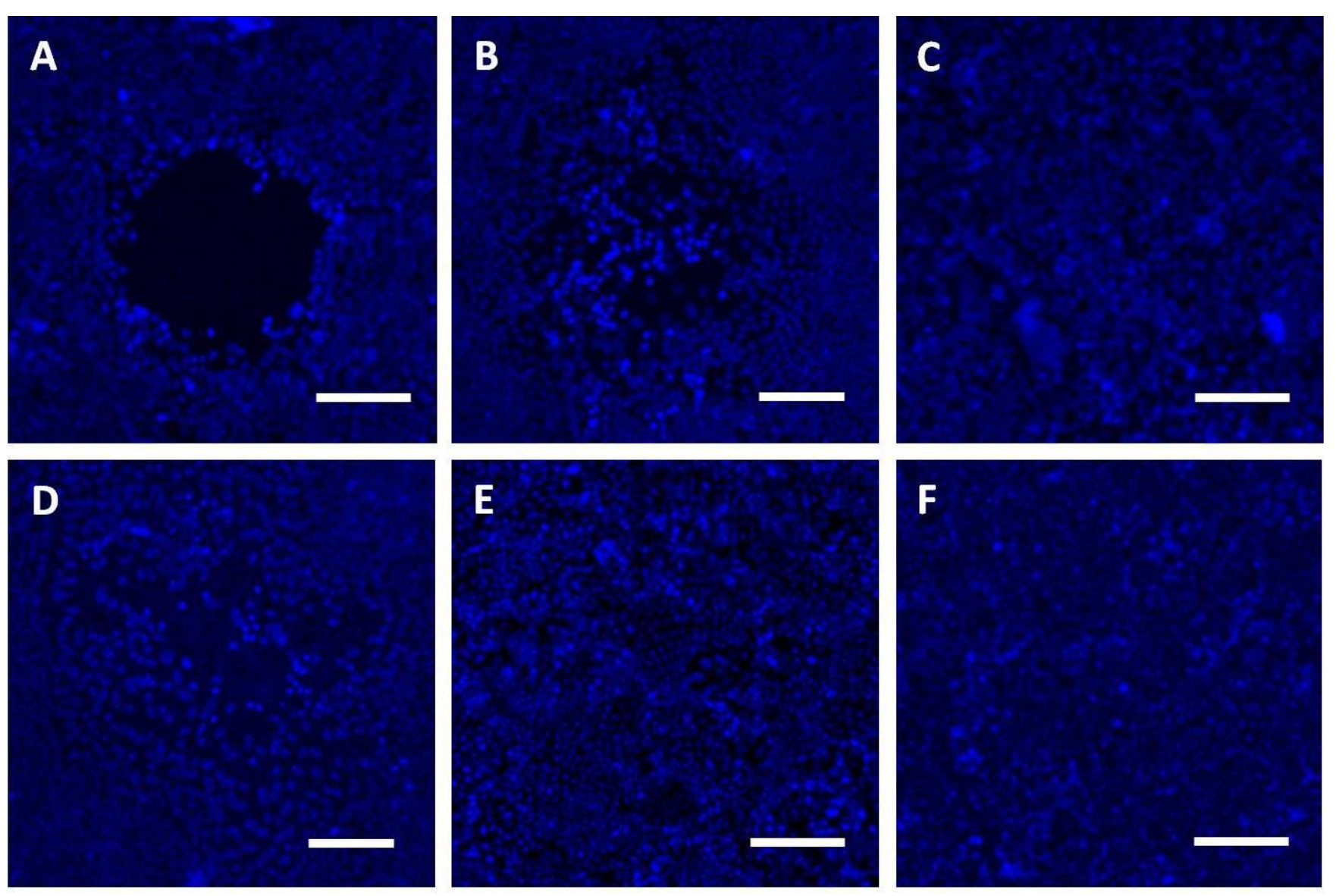

531 Fig. 5. Representative confocal laser-scanning microscopy images of Caco-2 cell monolayers with Hoechst 53233342 nuclei staining. A: Monolayer upon $2 \mathrm{~h}$ permeation study with microcontainers at direct contact, B: 533 Monolayer upon $2 \mathrm{~h}$ permeation study with microcontainers fixed at a $0.2 \mathrm{~mm}$ distance, C: Monolayer upon $2 \mathrm{~h}$ 534 permeation study with microcontainers fixed at a $0.5 \mathrm{~mm}$ distance, D: Monolayer after $24 \mathrm{~h}$ incubation upon $2 \mathrm{~h}$ 535 permeation study with microcontainers at direct contact, E: Monolayer after $2 \mathrm{~h}$ exposure to a solution of 0.1 $536 \mathrm{mM}$ insulin and $3 \mathrm{mM} \mathrm{C} 10$ with a chip of empty microcontainers, F: Control monolayer upon $2 \mathrm{~h}$ exposure to 537 hHBSS. Images have been adjusted for brightness/contrast and smooth processed using ImageJ. Scale bars 538 represent $100 \mu \mathrm{m}(\mathrm{n}=2)$. 


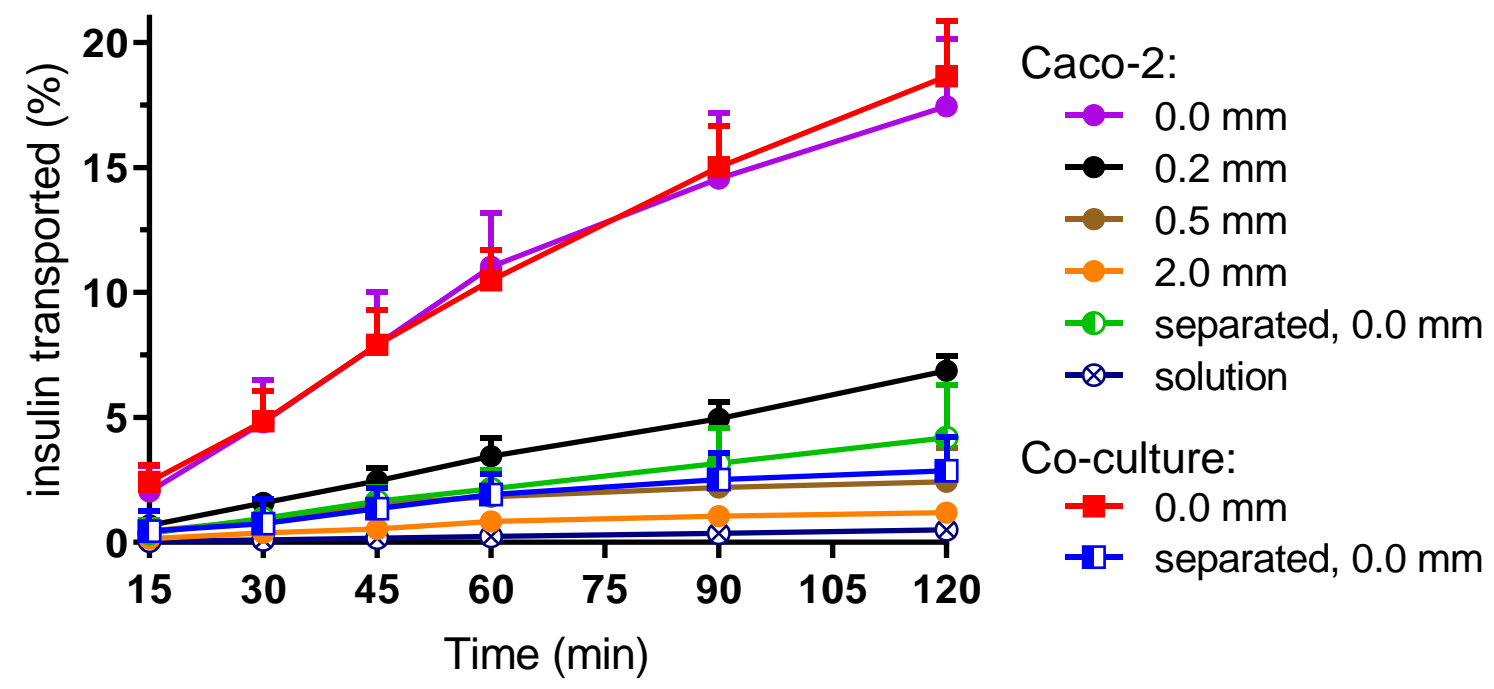

539

540 Fig. 6. Combined plot of all eight insulin transport profiles of insulin from microcontainers across Caco-2 or 541 Caco-2/HT29-MTX-E12 co-culture monolayers. Microcontainers were filled with insulin and $\mathrm{C}_{10}$ either; 542 premixed $(1: 1 \mathrm{w} / \mathrm{w})$, indicated with filled symbols, or individually, indicated with half-filled symbols, and 543 compared with a solution of $0.1 \mathrm{mM}$ insulin and $3 \mathrm{mM} \mathrm{C}_{10}(1: 1 \mathrm{w} / \mathrm{w})$ in combination with an empty 544 microcontainer chip, indicated with $\otimes$. Distance between the microcontainers and the Caco- 2 cell monolayer 545 was varied between 0-2 $\mathrm{mm}$ for the microcontainers loaded with premixed insulin and $\mathrm{C}_{10}$. All studies were 546 carried out in $10 \mathrm{mM}$ hHBSS with $\mathrm{pH} 7.4$ and $0.05 \%(\mathrm{w} / \mathrm{v}) \mathrm{BSA}$ at $37^{\circ} \mathrm{C}$. The graphs are expressed as mean + $547 \mathrm{SD}(\mathrm{n}=3)$. Increased number of passages $(\mathrm{n}=7)$ for direct Caco-2 monolayer-microcontainer contact $(0.0 \mathrm{~mm})$ 548 were carried out to ensure comparability across passages. 